Voix et Images

voixetimages

\title{
Misères de l'édition théâtrale
}

Lucie Robert

Volume 12, numéro 2 (35), hiver 1987

Jacques Brault

URI : https://id.erudit.org/iderudit/200645ar

DOI : https://doi.org/10.7202/200645ar

Aller au sommaire du numéro

\section{Éditeur(s)}

Université du Québec à Montréal

\section{ISSN}

0318-9201 (imprimé)

1705-933X (numérique)

Découvrir la revue

\section{Citer cet article}

Robert, L. (1987). Misères de l'édition théâtrale. Voix et Images, 12(2), 339-342. https://doi.org/10.7202/200645ar d'utilisation que vous pouvez consulter en ligne.

https://apropos.erudit.org/fr/usagers/politique-dutilisation/ 


\section{Dramaturgie}

\section{Misères de l'édition théâtrale}

\section{par Lucie Robert, Université du Québec à Montréal}

Il est un fait bien connu: l'édition thêâtrale n'existe qu'en fonction des programmes scolaires, où la dramaturgie est enseignée comme un genre littéraire. Cette fonction de l'édition théâtrale impose des choix et des politiques éditoriales particulières. Les textes dramatiques publiés doivent se suffire à eux-mêmes. On doit pouvoir les lire sans le support visuel de la mise en scène. Les textes publiés sont donc aussi les plus classiques, ce qui explique en partie comment il se fait que, dans les meilleures années, sur dix pièces créées. quatre seulement sont éditées. Les quelques maisons qui acceptent de publier des textes dramatiques ont chacune des objectifs particuliers. J'ai renoncé depuis longtemps à comprendre ceux du Noroît, qui n'édite qu'un seul dramaturge, l'ineffable Jean Daigle. Si les choix de Stanké n'ont de sens qu'en regard du marché scolaire, ceux des Éditions de la Pleine Lune ne peuvent être compris qu'en fonction de l'ensemble de leur catalogue: on y édite les textes dramatiques écrits par des écrivaines connues surtout pour leur œuvre romanesque ou poétique. C'est à la longue seulement que Jovette Marchessault a pu s'imposer comme dramaturge. Les deux principaux éditeurs de théâtre québécois, Leméac et vlb, partagent certaines conceptions de la dramaturgie, la seconde ayant d'ailleurs, lors de sa fondation, rapatrié certains auteurs. L'un et l'autre connaissent des difficultés financières chroniques qui n'èncouragent guère la promotion des nouvelles écritures théâtrales, quoique Leméac, sous la direction d'Yves Dubé, ait tenté certaines percées, plutôt ponctuelles, auprès de publics plus spécialisés comme le public féministe ou le public du jeune théâtre. Reste à voir si Jacques Lanctôt pourra assurer la survie, chez vlb, de la collection de théâtre et si Pierre Filion, qui prend la succession d'Yves Dubé à la direction littéraire de Leméac, saura insuffler une vie nouvelle à la maison. L'édition théâtrale n'est pas au bout de ses peines.

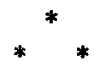

Dans sa collection de poche, Stanké réédite «Je m'égalomane à moimême...!", monologues de Sol que Marc Favreau présentait en spectacle en 1982. Écrits dans une conjoncture de crise (...enfin quelque chose d'économique), ces monologues se voulaient alors comme un miroir reflétant les préoccupations du public. La première partie du recueil renvoie donc à une histoire de l'âge de fer, où Sol donne sa vision du monde des affaires. Le précédent, le crédule, le marchant (sic), le défaillant, l'exagérant, l'agent immobile et les prioritaires en prennent pour leur rhume lorsqu'ils sont confrontés aux questions naives et aux comportements ingénus du clown. La seconde partie, plus diversifiée, renvoie aux transports, à la vie urbaine, à la campagne. Un monologue, "la Clef anglaise", demeure d'actualité en ces journées où se dispute à nouveau la question linguistique. $\bar{A}$ travers les 
problèmes et les énigmes de sa vie quotidienne, Sol conserve la volonté de rêver à faire l'enfant avec les oisifs pour amis. Le monologue qui clôt le recueil. "Cinémalomanie» donne au clown devenu réalisateur des envies de pouvoir et de puissance. Et je grandis... je grandis... j'ose ! je grandiose...! Je m'égalomane à moi-même... ! Rétrospectivement, c'est ce monologue qui donne son sens au recueil, en associant le vertige du pouvoir à l'emportement de la vie urbaine et aux conditions de la vie économique. Sol ne peut alors rater l'occasion de rappeler les réalisations de celui qu'il nomme le serpent de maire lors des oeufs limpides. Le livre s'ouvre et se ferme sur une série de photographies qui font la transition entre l'auteur et son personnage. comme un contre-spectacle vu des coulisses. Quoique cette présentation permette de visualiser le personnage de Sol, elle n'en recrée pas la voix qui est une dimension essentielle des monologues.

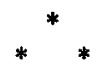

À propos de monologues, soulignons également la parution chez Leméac du texte d'un spectacle dont on avait beaucoup parlé lors de la création, le 6 juin 1980, au premier Festival de création de femmes, au Théâtre expérimental des femmes. Dans les Histoires de fantômes ${ }^{2}$. Francine Tougas, auteure et comédienne, tente une sorte d'exorcisme pour toutes les fois où (elle) a eu peur de dire et de parler. Seule en scène avec son accordéon, elle revit en quatre monologues reliés par des chansons. ses premières amours et ses fantasmes actuels, reflétant par là. les difficultés de toute une génération de femmes à vivre le féminisme sur le terrain des relations amoureuses. Quoique très court, le monologue suivant, l'Âge d'or, créé le 6 juin 1982 lors du deuxième Festival de création de femmes, est écrit comme une réflexion sur la situation d'une clocharde. La comédienne y interprète les deux rôles de la vieille folle et de la conteuse, jusqu'au moment où elle se rend compte que la première n'est que l'avenir dont la seconde a peur. Monologue dont la version finale fut créée au Théâtre expérimental des femmes, le 28 septembre 1982. Grandir est dédié à Marie-Mousse, la fille de l'auteure-comédienne. Francine Tougas y revit la richesse et les angoisses de sa maternité, tout en rendant hommage à la capacité de grandir des enfants. De caractère intimiste, liés à une étape de la réflexion féministe, les trois monologues perdent à être édités sans la chaleur de la voix de comédienne, sans l'amitié créée par le lieu scénique, sans l'environnement musical. Quoique réussis dans l'ensemble, les textes tombent à loccasion dans ce qui apparaît maintenant, cinq ou six ans plus tard, comme des lieux communs. L'aspect découpé des monologues gêne la lecture. Le papier ne peut ici rendre justice au spectacle.

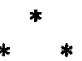

Histoire de fantômes également, Ici reposent en paix ${ }^{3}$ est la première édition d'un texte créé en février 1963 au théâtre Parabole, sous le titre les Morts-nés. De l'auteur, Jacques Duchesne, on ne possédait jusqu'à présent que le Quadrillé, créé et publié avec un certain succès en 1968. L'action se 
situe en 1955, dans un petit cimetière de Saint-Alphonse, et elle met en scène deux séries de personnages, les vivants, qui vivent sur terre, et les morts, qui vivent, si l'on peut dire, sous terre, ayant reconstitué une société en apparence sans contrainte. Deux vivants, Rosaire et Charly, découvrent par hasard le monde des morts. On les autorise à revenir sur terre à la condition d'assassiner le père Léon, dont la fiancée Mathilde, morte deux semaines avant le mariage. un demi-siècle plus tôt, attend toujours l'arrivée. Après le meurtre, qui est en fait un accident. Rosaire et Charly choisissent de retourner vivre chez les morts qu'ils trouvent plus joyeux que les vivants. Its se livrent à la police pour être jugés et condamnés. Sur le thème de la fuite, Jacques Duchesne fait ici le procès d'une société étouffante d'où la créativité est exclue. Au monde réglé et normé des vivants, il oppose le monde faux des morts où chacun et chacune invente son passé, où l'autorité n'est qu'un cérémonial vide de sens, où aucun espoir n'est permis. Retournés aux enfers, Rosaire et Charly ne découvrent que les fantômes de leur passé. Symboliquement, c'est un comédien qui fera sauter à la dynamite le monde recréé par les morts. Écrite comme une dénonciation de l'ère duplessiste, la pièce, après vingt-cinq ans, ne ressemble plus qu'à une fantaisie bien écrite où le grotesque fait parfois des incursions réussies.

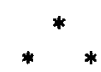

Pour sa part, la dramaturge Marie Laberge publie deux courtes pièces. L'Homme gris ${ }^{4}$ fut créé à la salle Fred-Barry le 13 septembre 1984. Reprise en lecture publique à Paris, lors des Internationaux de langue française, la pièce fut également jouée "en version française» (sic) au Théâtre de Bobigny le 12 février 1986. Drame à deux personnages, l'Homme gris oppose un père à sa fille, ancienne anorexique, mariée à dix-neuf ans. Parce qu'il la croit battue par son mari, le père a utilisé un faux prétexte pour ramener sa fille sous le toit familial. La scène se passe dans un motel, à mi-chemin, alors que la pluie et la nuit tombante les ont forcés à s’arrêter. Dans cette chambre minuscule, le père livre peu à peu à sa fille les motifs de son intervention et, tout en calant une bouteille de gin, lui raconte ce que fut vraiment sa vie à lui. "Gris" ici renvoie donc à la fois à l'ivresse qui le gagne au cours de la nuit qu’à l'évaluation de ses motivations qui se situent quelque part entre l'amour qu'il voue à sa fille, son sens du devoir et sa préoccupation de sauver les apparences. La réaction de Christine, qui, de toute la pièce, ne dit pas trois phrases, va du dégoût à un début d'affection puis au meurtre. L'écriture de Marie Laberge a ici encore un effet saisissant. Du récit du père se dégage la violence avec laquelle il étouffe les siens. L'Homme gris est suivi d'un texte trop court, Éva et Évelyne, créé au Théâtre du Vieux-Québec le 10 janvier 1979, où deux souurs, restées célibataires, doivent à soixante ans, faire face à leur solitude et assumer, quoique trop tard, leur peur du monde en général et des hommes en particulier.

1. Marc Favreau, «Je m'égalomane à moi-même...!», illustrations de Marie-Claude Favreau, présentation de. Micheline Gérin, Montréal, Stanké, 1986, 179 p. (10/10 monologues, no 88). 
342 VOIX \& IMAGES/35, hiver 1987

2. Francine Tougas. Histoires de fantômes. L'âge d'or. Grandir, Montréal, Leméac. 1985, 136 p. (Théâtre, no 146).

3. Jacques Duchesne. Ici reposent en paix. Montréal, Leméac. 1985. 130 p. (Thêâtre. no 148).

4. Marie Laberge. l'Homme gris suivi de Eva et Evelyne. Théâtre. Montréal, vlb éditeur. $1986.78 \mathrm{p}$. 